\title{
Human Pre-Implantation Embryos Are Permissive to SARS-CoV-2 Entry
}

Mauricio Montano $^{1 *}$, Andrea R. Victor ${ }^{2,3 *}$, Darren K. Griffin ${ }^{3}$, Tommy Duong ${ }^{4}$, Nathalie Bolduc $^{4}$, Andrew Farmer ${ }^{4}$, Vidur Garg ${ }^{5}$, Anna-Katerina Hadjantonakis ${ }^{5}$, Frank L.

Barnes $^{2}$, Christo G. Zouves ${ }^{2}$, Warner C. Greene ${ }^{1,6}$, and Manuel Viotti ${ }^{2,7 \#}$

* equal contribution

\# corresponding author

${ }^{1}$ Gladstone Institutes, San Francisco, California, USA

${ }^{2}$ Zouves Fertility Center, Foster City, California, USA

${ }^{3}$ School of Biosciences, University of Kent, Canterbury, UK

${ }^{4}$ Takara Bio USA, Inc., Mountain View, California, USA

${ }^{5}$ Developmental Biology Program, Sloan Kettering Institute, Memorial Sloan Kettering Cancer Center, New York, New York, USA.

${ }^{6}$ Departments of Medicine, Microbiology and Immunology, University of California, San

Francisco, San Francisco, California, United States of America

${ }^{7}$ Zouves Foundation for Reproductive Medicine, Foster City, California, USA 
Abstract

Vertical transmission of SARS-CoV-2, the virus responsible for COVID-19, from parents to early embryos during conception could be catastrophic, but is contingent on the susceptibility of cells of the embryo to infection. Because presence of the SARS-CoV-2 virus has been reported in the human reproductive system, we assessed whether pre-implantation embryos are permissive to SARSCoV-2 entry. RNA-seq and immunostaining studies revealed presence of two key entry factors in the trophectoderm of blastocyst-stage embryos, the ACE2 receptor and the TMPRSS2 protease. Exposure of blastocysts to fluorescent reporter virions pseudotyped with the SARS-CoV-2 Spike (S) glycoprotein revealed S-ACE2 dependent entry and fusion. These results indicate that human pre-implantation embryos can be infected by SARS-CoV-2, a finding pertinent to natural human conceptions and assisted reproductive technologies during and after the COVID-19 pandemic. 


\section{Introduction}

Coronavirus disease 2019 (COVID-19) has emerged as an unexpected, novel, and devastating pandemic upending life around the globe ${ }^{1}$. Entry of severe acute respiratory syndrome coronavirus 2 (SARS-CoV-2), the infectious agent responsible for COVID$19^{2}$, requires interactions of its surface glycoprotein Spike (S) with two 'entry' factors on the target cell: engagement of the receptor angiotensin-converting enzyme 2 (ACE2) by $S$ and cleavage of $S$ by the serine protease TMPRSS2 $2^{3,4}$. These binding and processing steps lead to subsequent endocytosis of virions and fusion within the late endosome ${ }^{4}$.

The full repertoire of cell and tissue types that SARS-CoV-2 can infect is now being defined ${ }^{1,5}$. Expression of SARS-CoV-2 cell entry factors has been described in a wide assortment of human cells ${ }^{5}$, and in COVID-19 patients, SARS-CoV-2 virus has been detected in various organs ${ }^{6-8}$. Infected individuals can also exhibit a range of symptoms spanning beyond lung-related problems, to include disease in the intestine, heart, kidney, vasculature, and liver ${ }^{6,8-12}$. Within the female and male reproductive systems, expression of SARS-CoV-2 entry factors is present in cells of the ovaries, uterus, vagina, testis, and prostate ${ }^{5,13-16}$. The virus is also detectable in the semen of infected males ${ }^{17}$.

The possibility of vertical transmission of SARS-CoV-2 to embryos during or shortly after fertilization is concerning, but is contingent on cells of the embryo being permissive to the virus. We now confirm expression of key entry factors for SARS-CoV2 on cells in the embryonic trophectoderm and demonstrate experimentally that reporter 
bioRxiv preprint doi: https://doi.org/10.1101/2021.01.21.427501; this version posted January 21, 2021. The copyright holder for this preprint (which was not certified by peer review) is the author/funder, who has granted bioRxiv a license to display the preprint in perpetuity. It is made available under aCC-BY-ND 4.0 International license.

virions pseudotyped with SARS-CoV-2 S can successfully enter cells of the embryo through S binding to ACE2 receptors. 


\section{Materials}

\section{Human Embryos}

All embryos used in this study were surplus samples from fertility treatment and in vitro fertilization, donated strictly for research by signed informed consent. Ethical approval for this project was obtained through the IRB of the Zouves Foundation for Reproductive Medicine (OHRP IRB00011505). For the RNA-seq experiment, embryos were of various ethnic backgrounds and comprised a mix of euploid and aneuploid samples based on evaluation by pre-implantation genetic testing for aneuploidy (PGT-A) ${ }^{18}$ (Suppl. Table 1). For immunofluorescence and infection experiments, embryos were either untested or assessed by PGT-A, and included a mix of euploid, mosaic, and aneuploid samples (samples with aneuploidies in chromosomes $\mathrm{X}$ or 21 , respectively encoding ACE2 and TMPRSS2, were excluded).

\section{RNA-seq and Expression Analysis}

Trophectoderm (TE) biopsies containing 5-10 cells from blastocyst-stage embryos $(n=24)$ were processed for RNA-seq using a commercial kit (Takara Bio, SMART-Seq v4 Ultra Low Input RNA Kit for Sequencing) following the user manual. The resulting cDNAs were converted to libraries using Illumina Nextera XT kit (with modified protocol according to SMART-Seq v4 user manual). The resulting libraries were pooled and sequenced on an Illumina NextSeq 550 with a MidOutput cartridge at $2 \times 75$ cycles. The sequencing reads in Fastq files were down-sampled to $6 \mathrm{M}$ total reads, aligned to the human genome assembly (hg38), and the number of transcripts per million (TPM) was 
determined using the CLC Genomics Workbench 12 (Qiagen). Results were mined for expression of factors implicated in SARS-CoV-2 infection. Violin plots were prepared with PlotsOfData ${ }^{19}$.

\section{Immunofluorescence}

Blastocysts were immersed in fixation buffer containing 4\% paraformaldehyde (EMS no. 15710 ) and $10 \%$ fetal bovine serum (FBS; Seradigm 1500-050) in phosphate-buffered saline (PBS; Corning MT21040CM) for 10 minutes ( $\mathrm{min}$ ) at room temperature (rt), followed by three 1-min washes at rt in PBS with 10\% FBS. Embryos were blocked in 2\% horse serum (Sigma H0146) and 0.1\% saponin (Sigma S7900) in PBS (blocking solution) for 1 hour (h) at rt and then incubated with primary antibodies diluted in blocking solution overnight at $4{ }^{\circ} \mathrm{C}$. Embryos were then washed three times for 5 min each in PBS at rt prior to incubation with secondary antibodies. Secondary antibodies diluted in blocking solution were applied for $1 \mathrm{~h}$ at $4{ }^{\circ} \mathrm{C}$. Embryos were then washed twice for 5 min each in PBS and subsequently incubated with $5 \mu \mathrm{g} / \mathrm{ml}$ Hoechst 33342 (Invitrogen) in PBS for 5 min. Finally, embryos were washed twice for 5 min each in PBS prior to mounting for imaging. The following primary antibodies were used: goat anti-ACE2 (R\&D Systems AF933, 1:100), mouse anti-TMPRSS2 (Developmental Hybridoma Bank P5H9-A3, 3.2 $\mu \mathrm{g} / \mathrm{ml}$ ). The following secondary Alexa Fluor-conjugated antibodies (Invitrogen) were used at a dilution of 1:500: donkey anti-goat Alexa Fluor 568 (A10042), donkey anti-mouse Alexa Fluor 488 (A21202). DNA was visualized using Hoechst 33342. For all immunofluorescence experiments, $n=5$ independent biological replicates were used. 


\section{Pseudotyped Virion Production}

For production of HIV-1 NL-43AEnv-eGFP SARS CoV-2 S pseudotyped virus particles, 293T cells were plated at $3.75 \times 10^{6}$ cells in a T175 flask. $24 \mathrm{~h}$ post plating the cells were transfected by PEI transfection reagent (Sigma) with $90 \mu \mathrm{g}$ of PEI, $30 \mu \mathrm{g}$ of HIV-1 NL4 $\Delta$ Env-eGFP (NIH AIDS Reagent Program) and $3.5 \mu \mathrm{g}$ of pCAGGS SARS CoV-2 S Glycoprotein (NR52310, BEI) in a total of $10 \mathrm{ml}$ of Opti-MEM media (Invitrogen). The day following transfection the media was changed to DMEM10 complete media and placed at $37^{\circ} \mathrm{C}$ and $5 \% \mathrm{CO}_{2}$ for $48 \mathrm{~h}$. At $48 \mathrm{~h}$ the supernatant was harvested, filtered by $0.22 \mu \mathrm{m}$ Steriflip filters (EMD, Millipore) and then concentrated by ultracentrifugation for $1.5 \mathrm{~h}$ at $4{ }^{\circ} \mathrm{C}$ and $25 \mathrm{~K} \mathrm{rpm}$. After concentration the supernatant was removed and virus particle pellets were resuspended in cold 1xPBS containing 1\% FBS, aliquots were stored at $-80^{\circ} \mathrm{C}$. For production of control virus particles not expressing the SARS CoV$2 \mathrm{~S}$ glycoprotein (Bald), the same procedure was used but with the omission of the pCAGGS SARS CoV-2 S vector transfection. SARS and MERS pseudotyped virus particles were produced using the same procedure, substituting the SARS CoV-2 S expression vector with either pcDNA3.1(+) SARS S or pcDNA3.1(+) MERS S.

For production of VSV $\Delta$ G SARS CoV-2 S pseudotyped virus particles, 293T cells were plated at $1.8 \times 10^{6}$ cells in a T175 flask. $24 \mathrm{~h}$ post plating the cells were transfected by PEI transfection reagent (Sigma) with $90 \mu \mathrm{g}$ of PEI, $30 \mu \mathrm{g}$ of pCAGGS SARS CoV-2 S Glycoprotein (NR52310, BEI) in a total of $10 \mathrm{~mL}$ of Opti-MEM media (Invitrogen). One day after transfection the media was removed, the cells are washed with 1xPBS and DMEM10 complete media was added. Once the media was changed the cells were 
infected with VSV $\Delta G$ VSVg virus (Sandia) at an MOI of 1 or higher. The infection media is changed after $4 \mathrm{~h}$, the cells are washed with $1 \mathrm{xPBS}$ and DMEM10 supplemented with $20 \%$ anti-VSVg hybridoma supernatant (ATCC CRL-2700). At $24 \mathrm{~h}$ the supernatant was harvested, filtered by $0.22 \mu \mathrm{m}$ Steriflip filter (EMD, Millipore) and then concentrated by ultracentrifugation for $1.5 \mathrm{~h}$ at $4{ }^{\circ} \mathrm{C}$ and $25 \mathrm{~K} \mathrm{rpm}$. Supernatant was removed and virus particle pellets were resuspended in cold 1xPBS containing 1\% FBS, aliquots were stored at $-80^{\circ} \mathrm{C}$. For production of control virus particles not expressing the SARS CoV$2 \mathrm{~S}$ glycoprotein (Bald), the same procedure was used but with the omission of the pCAGGS SARS CoV-2 S vector transfection on day 2.

SARS and MERS pseudotyped virus particles were produced using the same procedures, substituting the SARS CoV-2 S expression vector with either pcDNA3.1(+) SARS S or pcDNA3.1(+) MERS S vectors respectively.

\section{Virion Infection}

For viral infection experiments, blastocyst-stage embryos $(n=94)$ were hatched from zona pellucidas mechanically, and transferred to flat bottom 96 well plates in $100 \mu \mathrm{l}$ embryo culture media. Either HIV-1 NL-43AEnv-eGFP SARS CoV-2 S pseudotyped virions (100ng/p24), or VSV $\triangle$ G SARS CoV-2 S pseudotyped virions (MOI=0.1), were added to the embryos. Bald (not expressing $\mathrm{S}$ glycoprotein) virions and mock infection conditions were included for each infection experiment. After the addition of the virions, the embryos were spinoculated at $200 \mathrm{~g}$ for $2 \mathrm{~h}$ at $\mathrm{rt}$. Upon completion of the spinoculation an additional $100 \mu$ of embryo culture media was added to each well and the cultures were placed at $37{ }^{\circ} \mathrm{C}$ and $5 \% \mathrm{CO}_{2}$. For the HIV-1 NL-43 $\Delta$ Env-eGFP based 
infections embryos were monitored for fluorescence at $24-48 \mathrm{~h}$ post-spinoculation. For the VSV $\Delta \mathrm{G}$ based infections embryos were monitored for fluorescence at $12-24 \mathrm{~h}$ postspinoculation. Additional controls included conditions with either $10 \mu \mathrm{g}$ of anti-ACE2 antibody (AF933, R\&D Systems), anti-SARS CoV-2 S Neutralizing antibody (SAD-S35, ACRO) or anti-Human IgG Kappa (STAR 127, Bio-Rad) control antibody.

\section{Microscopy}

Embryos were placed into 35-mm glass-bottom dishes (MatTek). For epifluorescence microscopy, embryos were imaged with a EVOS M5000 Imaging System employing a LPanFL PH2 20X/0.40 lens, and fluorescence light cube for GFP (470/525 nm) and transmitted light. For confocal microscopy of immunostained embryos, samples were placed within microdrops of a $4 \mathrm{mg} / \mathrm{ml}$ solution of BSA (Sigma) in PBS. Images were acquired using a Zeiss LSM880 laser-scanning confocal microscope, equipped with an oil-immersion Zeiss EC Plan-Neofluar 40x/NA1.3/WD0.17mm. Z-stacks were acquired through whole embryos with an optical section thickness of $1 \mu \mathrm{m}$. Fluorescence was excited with a 405-nm laser diode (Hoechst), a 488-nm Argon laser (Alexa Fluor 488), and a 561-nm DPSS laser (Alexa Fluor 568). For confocal microscopy of infected embryos, samples were stained with Hoechst 33342, and images were acquired using an Olympus FV3000RS laser-scanning microscope using a 40X UPLXAPO (NA=0.95). Embryos were simultaneously scanned for Hoechst and GFP using the 405-nm and 488-nm lasers. RapidZ series were taken through the entire volume of the imaged embryos in $3 \mu \mathrm{m}$ steps. 
bioRxiv preprint doi: https://doi.org/10.1101/2021.01.21.427501; this version posted January 21, 2021. The copyright holder for this preprint (which was not certified by peer review) is the author/funder, who has granted bioRxiv a license to display the preprint in perpetuity. It is made available under aCC-BY-ND 4.0 International license. 


\section{Results}

\section{Cells of the Embryo Express Genes Required for SARS-CoV-2 Infection}

We reasoned that within the pre-implantation period of human development, embryos in the blastocyst stage are particularly vulnerable as they lose their protective zona pellucida (ZP) that counters the threat of many foreign agents ${ }^{20}$. The trophectoderm, which is the precursor to the the placenta ${ }^{21}$, is located at the surface of the blastocyst and may be the specific target of infecting viruses. Hence, we focused our attention on the trophectoderm and evaluated its permissiveness to SARS-CoV-2 infection.

Two prior publications have described ACE2 and TMPRSS2 expression in blastocyst-stage pre-implantation embryos ${ }^{5,22}$ based on analysis of publicly available RNA-seq datasets from a single ethnic group (East Asian/Chinese) $)^{23-25}$. To determine whether this pattern of gene expression is observed in more diverse populations, we performed RNA-seq on a group of 24 human blastocysts from multiple ethnic backgrounds (Suppl. Table 1). ACE2 transcripts were detected in trophectoderm biopsies comprising 5-10 cells in 23 of 24 embryos (95.8\%), and TMPRSS2 transcripts in biopsies from all 24 embryos (Fig.1A). We evaluated the expression of 22 additional human genes proposed to be involved in the SARS-CoV-2 life cycle ${ }^{5}$ (Fig.1B). Expression was confirmed for genes encoding putative alternate receptors (BSG/CD147, ANPEP) and proteases (CTSB, CTSL, TMPRSS4). Transcripts for DPP4, encoding the receptor used by MERS-CoV to enter cells, were either absent or expressed at very low levels in our samples. 
Genes for two factors apparently required for SARS-CoV-2 genome replication, TOP3B and ZCRB1/MADP1, were expressed respectively at low and high levels. Among the genes encoding factors proposed to control trafficking and/or assembly of viral components and which are known to interact with SARS-CoV-2 proteins, RHOA, RAB10, RAB14, RAB1A, AP2M1, and CHMP2A exhibited high levels of expression while AP2A2 and TAPT1 were expressed at low levels. Together, these transcriptomic profiling data indicate that trophectoderm cells express many key factors required for SARS-CoV-2 entry and subsequent replication.

\section{SARS-CoV-2 Entry Factors Localize to the Membrane of Trophectoderm Cells}

To evaluate the presence and localization of entry factors in trophectoderm cells, we performed immunofluorescence and confocal imaging for ACE2 and TMPRSS2 in blastocysts. Both factors were readily detectable in cells of the trophectoderm; ACE2 was enriched on cellular membranes, as evidenced by strong signal at cell-cell junctions (Fig. 2A), while the TMPRSS2 pattern was more diffuse, localizing to both cell membranes and within the cytoplasm but not nucleus (Fig. 2B). The inner cell mass (ICM) was not evaluated, since the immunofluorescence protocol was not optimized for penetration of antibodies through cell layers. Localization of ACE2 and TMPRSS2 protein suggests that pre-implantation embryos are potentially permissive to SARSCoV-2 entry. 


\section{Human Embryos are Receptive to Entry by SARS-CoV-2 Pseudotyped Reporter Virions}

To test the susceptibility of embryos to SARS-CoV-2 infection, we evaluated the entry of viral agents expressing the SARS-CoV-2 S protein. In the first series of experiments (see Table 1), we used an HIV-based reporter virion lacking its native viral entry factor Env, and encoding the green fluorescent protein (GFP). Embryos exposed to control media or media containing the original non-pseudotyped 'bald' reporter virus displayed no fluorescence and appeared healthy 24-48 hours after mock spinoculation (inoculation by centrifugation) (Suppl. Fig. 1). However, when embryos were exposed to the reporter virus pseudotyped with the S protein from SARS-CoV-2, several showed robust GFP signal in numerous trophectoderm cells (Fig. 3A). Some embryos showed both strong GFP signal and evidence of cell degradation (Fig.3A and Suppl. Fig. 1). Treatment of the blastocysts with neutralizing anti-S antibodies markedly decreased GFP fluorescence to a limited number of puncta (Suppl. Fig. 1).

In the second experimental series (see Table 1), we used a vesicular stomatitis virus lacking the cell entry factor G envelope protein (VSV $\Delta \mathrm{G}$ ), and encoding GFP as a reporter. No fluorescence was detected when embryos were exposed to control media or media containing the non-pseudotyped 'bald' virions . Conversely, several samples exhibited GFP when exposed to the reporter virus pseudotyped with the SARS-CoV-2 S protein (Fig. 3B). Again, some of the infected embryos showed evidence of cellular degradation 24-48 h after spinoculation (Fig. 3B and Suppl. Fig. 1). Addition of a neutralizing antibody targeting either S or ACE2 strongly reduced GFP expression, while a control, non-specific anti-lgG antibody produced no inhibitory effects (Suppl. 
Fig. 1). When the VSV $\Delta$ G-based reporter virus was pseudotyped with the $S$ protein from SARS-CoV-1, which also utilizes the ACE2 receptor for cell entry, embryos again displayed GFP signal and occasional evidence of cellular degradation (Suppl. Fig. 1). Conversely, reporter virus pseudotyped with the S protein from MERS-CoV, which depends on the dipeptidyl peptidase 4 (DPP4) receptor for cell entry, produced no GFP signal (Suppl. Fig. 1). Together, these pseudotyped-virion experiments indicate that pre-implantation embryos are permissive to SARS-CoV-2 entry (and likely SARS-CoV-1 entry), involving interactions of S proteins with the ACE2 receptor. 


\section{Discussion}

The findings of this study demonstrate the permissiveness of human preimplantation embryos to SARS-CoV-2 entry. Transcript and protein profiling show the presence of the required receptor and protease in cells of the trophectoderm, the embryo's outer cell layer, which is essential for embryo implantation and later in pregnancy forms the placenta. Pseudotyped virion experiments indicate effective entry is achieved when SARS-CoV-2 S binds to human ACE2 receptors.

Our RNA-seq experiments show that embryos from multiple ethnic backgrounds express the canonical entry factor genes ACE2 and TMPRSS2 in trophectoderm cells. These findings confirm and extend prior reports of ACE2 and TRMPRSS2 embryonic expression in a single ethnic group (East Asian/China) ${ }^{23-25}$. The localization of ACE2 we observe on the membrane of trophectoderm cells is in agreement with a previous study employing a different commercially-available anti-ACE2 antibody for immunofluorescence microscopy ${ }^{26}$. In addition, we detect the TMPRSS2 protein in the same cell population of the embryo, a strong indication that SARS-CoV-2 could indeed enter trophectoderm cells via the canonical ACE2-TMPRSS2 pathway.

The experiments using reporter virions confirm our hypothesis. Only virions pseudotyped with the S protein could infect cells of the embryo, and interfering with either S or ACE2 with neutralizing antibodies reduces infection by the pseudotyped virions, implicating a functional interplay between S and ACE2 for cell entry. Embryos also displayed evidence of infection by reporter virions pseudotyped with the S protein from SARS-CoV-1 (which similarly uses ACE2 for entry) but not with the S protein from 
MERS-CoV (which uses DPP4 for entry), again suggesting that ACE2 functions as an effective coronavirus receptor in trophectoderm cells.

The finding that pre-implantation embryos are susceptible to SARS-CoV-2 infection raises the possibility of viral transmission from either the mother or father to the developing embryo. Although the data remains limited, vertical transmission of SARSCoV-2 between pregnant mothers and fetuses has been reported ${ }^{27-30}$, albeit considerably later in pregnancy. Of note, the studies implicate the placenta, which develops from the trophectoderm, as the principal site of transmission ${ }^{29,31}$. Vertical transmission to the embryo before implantation would necessarily require exposure to SARS-CoV-2 virions at this precise stage. While cell entry factors are present in various cells in the female reproductive tract ${ }^{13,16}$, to date there have been no confirmed reports of SARS-CoV-2 infection in those tissues ${ }^{32}$. For example, a study showed that none of 16 oocytes from two asymptomatic positive women contained detectable virus ${ }^{33}$. However, some evidence suggesting that infected males may transmit the virus is emerging. In one study, six of 38 male COVID-19 patients had detectable levels of SARS-CoV-2 in their semen ${ }^{17}$. Moreover, microlesions in any part of the male or female reproductive systems could translate to exposure of pre-implantation embryos to the virus since SARS-CoV-2 RNA has been detected in the blood of infected patients ${ }^{34}$. In comparison to embryos from natural conceptions, embryos generated by assisted reproductive technologies (ART) for treatment of infertility, such as in vitro fertilization (IVF), face additional avenues of potential viral exposure. These include exposure to virus shed by asymptomatically infected medical and laboratory personnel during handling of gametes, assisted conception, embryo culture, intrauterine transfer, 
or extended cryopreservation. Guidelines regarding best practices in the ART clinic during the COVID-19 pandemic have been recently described ${ }^{35-39}$, however we feel these recommendations merit revision in light of the data presented here.

An unexpected additional finding is the toxicity of the pseudotyped virions for infected cells. We observed various degrees of cell degradation in embryos that showed GFP expression, ranging from subtle to pronounced evidence of blebbing or cell debris with GFP positive puncta, and, in a few instances, total embryo demise. This was the case with both HIV-and VSV $\Delta$ G-based reporter virions. The cytotoxicity might be produced by $S$ engaging ACE2, resulting in signaling and activation of a cell death program in cells of the embryo. Alternatively, toxicity might occur as a result of transcription and translation of reporter virus genes. It will be interesting to assess the effects of live SARS-CoV-2 infection on these blastocysts.

SARS-CoV-2 infection in pregnant women is associated with increased risk of miscarriage, prematurity, and impaired fetal growth ${ }^{40}$. Such adverse fetal outcomes have mainly been attributed to COVID-19-related complications in pregnant patients ${ }^{40}$, but could also reflect infection of the fetus during pregnancy ${ }^{27-30}$. The present study further indicates that vertical transmission during pre-implantation stages might contribute to such complications and should not be ruled out. Given the trophectoderm's central role in implantation of an embryo into the maternal endometrium, compromised health of trophectoderm cells due to SARS-CoV-2 infection could altogether impede establishment of a pregnancy. Alternatively, lasting detrimental effects on the trophectoderm-derived placenta could affect the clinical outcome of an established pregnancy. Noting that our transcriptomic analysis revealed RNA presence of various 
factors associated with downstream steps of the SARS-CoV-2 viral life cycle, such as genome replication, trafficking and assembly ${ }^{5}$, the possibility of trophectoderm cells infecting surrounding tissues (maternal or fetal) after additional viral shedding cannot be excluded. Ultimately, population effects of the COVID-19 pandemic on fertility may become apparent when epidemiological data on pregnancies and birth rates become more readily available.

In summary, our finding that pre-implantation embryos are permissive to SARSCoV-2 entry highlights a potential vulnerability of these embryos in vivo. Additionally, the data presented here should prompt careful review of procedures surrounding in vitro fertilization during the COVID-19 pandemic and its aftermath. 


\section{References}

1. Morens, D.M. \& Fauci, A.S. Emerging Pandemic Diseases: How We Got to COVID-19. Cell 182, 1077-1092 (2020).

2. Zhu, N., et al. A Novel Coronavirus from Patients with Pneumonia in China, 2019. N Engl J Med 382, 727-733 (2020).

3. Zhou, P., et al. A pneumonia outbreak associated with a new coronavirus of probable bat origin. Nature 579, 270-273 (2020).

4. Hoffmann, M., et al. SARS-CoV-2 Cell Entry Depends on ACE2 and TMPRSS2 and Is Blocked by a Clinically Proven Protease Inhibitor. Cell 181, 271-280 e278 (2020).

5. Singh, M., Bansal, V. \& Feschotte, C. A Single-Cell RNA Expression Map of Human Coronavirus Entry Factors. Cell Rep 32, 108175 (2020).

6. Gao, Q.Y., Chen, Y.X. \& Fang, J.Y. 2019 Novel coronavirus infection and gastrointestinal tract. J Dig Dis 21, 125-126 (2020).

7. Puelles, V.G., et al. Multiorgan and Renal Tropism of SARS-CoV-2. N Engl J Med 383, 590-592 (2020).

8. Xiao, F., et al. Evidence for Gastrointestinal Infection of SARS-CoV-2. Gastroenterology 158, 1831-1833 e1833 (2020).

9. Goyal, P., et al. Clinical Characteristics of Covid-19 in New York City. N Engl J Med 382, 2372-2374 (2020).

10. Zhang, C., Shi, L. \& Wang, F.S. Liver injury in COVID-19: management and challenges. Lancet Gastroenterol Hepatol 5, 428-430 (2020).

11. Ellul, M.A., et al. Neurological associations of COVID-19. Lancet Neurol 19, 767783 (2020). 
12. Moriguchi, T., et al. A first case of meningitis/encephalitis associated with SARSCoronavirus-2. Int J Infect Dis 94, 55-58 (2020).

13. Henarejos-Castillo, I., Sebastian-Leon, P., Devesa-Peiro, A., Pellicer, A. \& DiazGimeno, P. SARS-CoV-2 infection risk assessment in the endometrium: viral infection-related gene expression across the menstrual cycle. Fertil Steril 114, 223-232 (2020).

14. Stanley, K.E., Thomas, E., Leaver, M. \& Wells, D. Coronavirus disease-19 and fertility: viral host entry protein expression in male and female reproductive tissues. Fertil Steril 114, 33-43 (2020).

15. Wang, Z. \& Xu, X. scRNA-seq Profiling of Human Testes Reveals the Presence of the ACE2 Receptor, A Target for SARS-CoV-2 Infection in Spermatogonia, Leydig and Sertoli Cells. Cells 9(2020).

16. Jing, Y., et al. Potential influence of COVID-19/ACE2 on the female reproductive system. Mol Hum Reprod 26, 367-373 (2020).

17. Li, D., Jin, M., Bao, P., Zhao, W. \& Zhang, S. Clinical Characteristics and Results of Semen Tests Among Men With Coronavirus Disease 2019. JAMA Netw Open 3, e208292 (2020).

18. Viotti, M. Preimplantation Genetic Testing for Chromosomal Abnormalities: Aneuploidy, Mosaicism, and Structural Rearrangements. Genes (Basel) 11(2020).

19. Postma, M. \& Goedhart, J. PlotsOfData-A web app for visualizing data together with their summaries. PLoS Biol 17, e3000202 (2019).

20. Litscher, E.S. \& Wassarman, P.M. Zona Pellucida Proteins, Fibrils, and Matrix. Annu Rev Biochem 89, 695-715 (2020).

21. Turco, M.Y. \& Moffett, A. Development of the human placenta. Development 146(2019). 
22. Weatherbee, B.A.T., Glover, D.M. \& Zernicka-Goetz, M. Expression of SARSCoV-2 receptor ACE2 and the protease TMPRSS2 suggests susceptibility of the human embryo in the first trimester. Open Biol 10, 200162 (2020).

23. Yan, L., et al. Single-cell RNA-Seq profiling of human preimplantation embryos and embryonic stem cells. Nat Struct Mol Biol 20, 1131-1139 (2013).

24. Xiang, L., et al. A developmental landscape of 3D-cultured human pregastrulation embryos. Nature 577, 537-542 (2020).

25. Zhou, F., et al. Reconstituting the transcriptome and DNA methylome landscapes of human implantation. Nature 572, 660-664 (2019).

26. Essahib, W., Verheyen, G., Tournaye, H. \& Van de Velde, H. SARS-CoV-2 host receptors ACE2 and CD147 (BSG) are present on human oocytes and blastocysts. J Assist Reprod Genet (2020).

27. Flaherman, V.J., et al. Infant Outcomes Following Maternal Infection with SARSCoV-2: First Report from the PRIORITY Study. Clin Infect Dis (2020).

28. Turan, O., et al. Clinical characteristics, prognostic factors, and maternal and neonatal outcomes of SARS-CoV-2 infection among hospitalized pregnant women: A systematic review. Int J Gynaecol Obstet (2020).

29. Vivanti, A.J., et al. Transplacental transmission of SARS-CoV-2 infection. Nat Commun 11, 3572 (2020).

30. Patane, L., et al. Vertical transmission of coronavirus disease 2019: severe acute respiratory syndrome coronavirus 2 RNA on the fetal side of the placenta in pregnancies with coronavirus disease 2019-positive mothers and neonates at birth. Am J Obstet Gynecol MFM 2, 100145 (2020).

31. Hosier, H., et al. SARS-CoV-2 infection of the placenta. J Clin Invest 130, 49474953 (2020). 
32. Segars, J., et al. Prior and novel coronaviruses, Coronavirus Disease 2019 (COVID-19), and human reproduction: what is known? Fertil Steril 113, 11401149 (2020).

33. Barragan, M., Guillen, J.J., Martin-Palomino, N., Rodriguez, A. \& Vassena, R. Undetectable viral RNA in oocytes from SARS-CoV-2 positive women. Hum Reprod (2020).

34. Wang, W., et al. Detection of SARS-CoV-2 in Different Types of Clinical Specimens. JAMA 323, 1843-1844 (2020).

35. https://www.asrm.org/globalassets/asrm/asrm-content/news-andpublications/covid-19/covidtaskforceupdate10.pdf.

36. Group, E.C.-W., et al. The calm after the storm: re-starting ART treatments safely in the wake of the COVID-19 pandemic. Hum Reprod (2020).

37. Maggiulli, R., et al. Assessment and management of the risk of SARS-CoV-2 infection in an IVF laboratory. Reprod Biomed Online 41, 385-394 (2020).

38. Veiga, A., et al. Assisted reproduction and COVID-19: a joint statement of ASRM, ESHRE and IFFS. Hum Reprod Open 2020, hoaa033 (2020).

39. Simopoulou, M., et al. Navigating assisted reproduction treatment in the time of COVID-19: concerns and considerations. J Assist Reprod Genet 37, 2663-2668 (2020).

40. Boushra, M.N., Koyfman, A. \& Long, B. COVID-19 in pregnancy and the puerperium: A review for emergency physicians. Am J Emerg Med (2020). 


\section{Legends}

Figure 1. Expression of Genes Involved in SARS-CoV-2 Infection in Embryo Cells.

Violin plots showing log10-normalized expression profiles obtained by RNA-seq performed on trophectoderm biopsies of blastocysts. Each data point represents one embryo. Each trophectoderm biopsy consisted of 5-10 cells.

(A) Canonical SARS-CoV-2 entry factors ACE2 and TMPRSS2

(B) Proposed alternative/ancillary mediators of SARS-CoV-2 entry, replication, traffic, and assembly.

Figure 2. Localization of ACE2 and TMPRSS2 in Embryos.

Maximum intensity projections (MIPs) of confocal z-stacks of blastocysts, showing nuclei (blue) and ACE2 or TMPRSS2 (white). Pink arrowheads point to cell membranes. Scale bars represent $50 \mu \mathrm{m}$ in low magnification panels, and $10 \mu \mathrm{m}$ in high magnification panels.

Figure 3. Embryo Infection by Reporter Virions Pseudotyped with the S protein of SARS-CoV-2.

Sample confocal MIP images of embryos infected with HIV-based (A) or VSV $\Delta$ G -based (B) reporter virions pseudotyped with the S protein from SARS-CoV-2. Pink arrowheads point to cells displaying robust GFP signal, white arrowheads point to evidence of cell degradation. Scale bars represent $20 \mu \mathrm{m}$. 


\section{Supplemental Figure 1. Reporter Virion Experiments Indicate Entry Into Cells of the Embryo Via SARS-CoV-2 S and ACE2.}

Embryos used in GFP reporter virion experiments, displaying merged brightfield with epifluorescence signal. Top set shows results from HIV-based virus, bottom set shows results from the VSV $\Delta$ G-based virus. Two representative images are shown per condition. Pink arrowheads point to cells displaying robust GFP signal, white arrowheads point to evidence of cell degradation, yellow arrowheads point to punctate GFP signal, and white asterisks indicate embryos manifesting poor health or complete demise. Scale bars represent $50 \mu \mathrm{m}$.

\section{Table 1. Summary of Experiments Using Reporter Virions.}

For each reporter virion (HIV- or VSV $\Delta \mathrm{G}$-based), the table indicates the experimental condition, the number of embryos used, and the number/percent of infected embryos as evidenced by GFP signal.

\section{Supplemental Table 1. Features of Embryos used in RNA-seq Experiment.}


bioRxiv preprint doi: https://doi.org/10.1101/2021.01.21.427501; this version posted January 21, 2021. The copyright holder for this preprint (which was not certified by peer review) is the author/funder, who has granted bioRxiv a license to display the preprint in perpetuity. It is made available under aCC-BY-ND 4.0 International license.

\section{Figures}

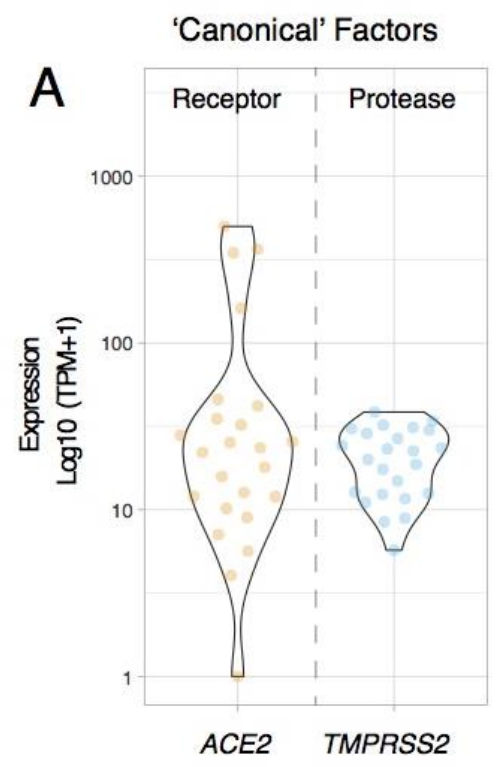

Proposed Alternative/Ancillary Factors

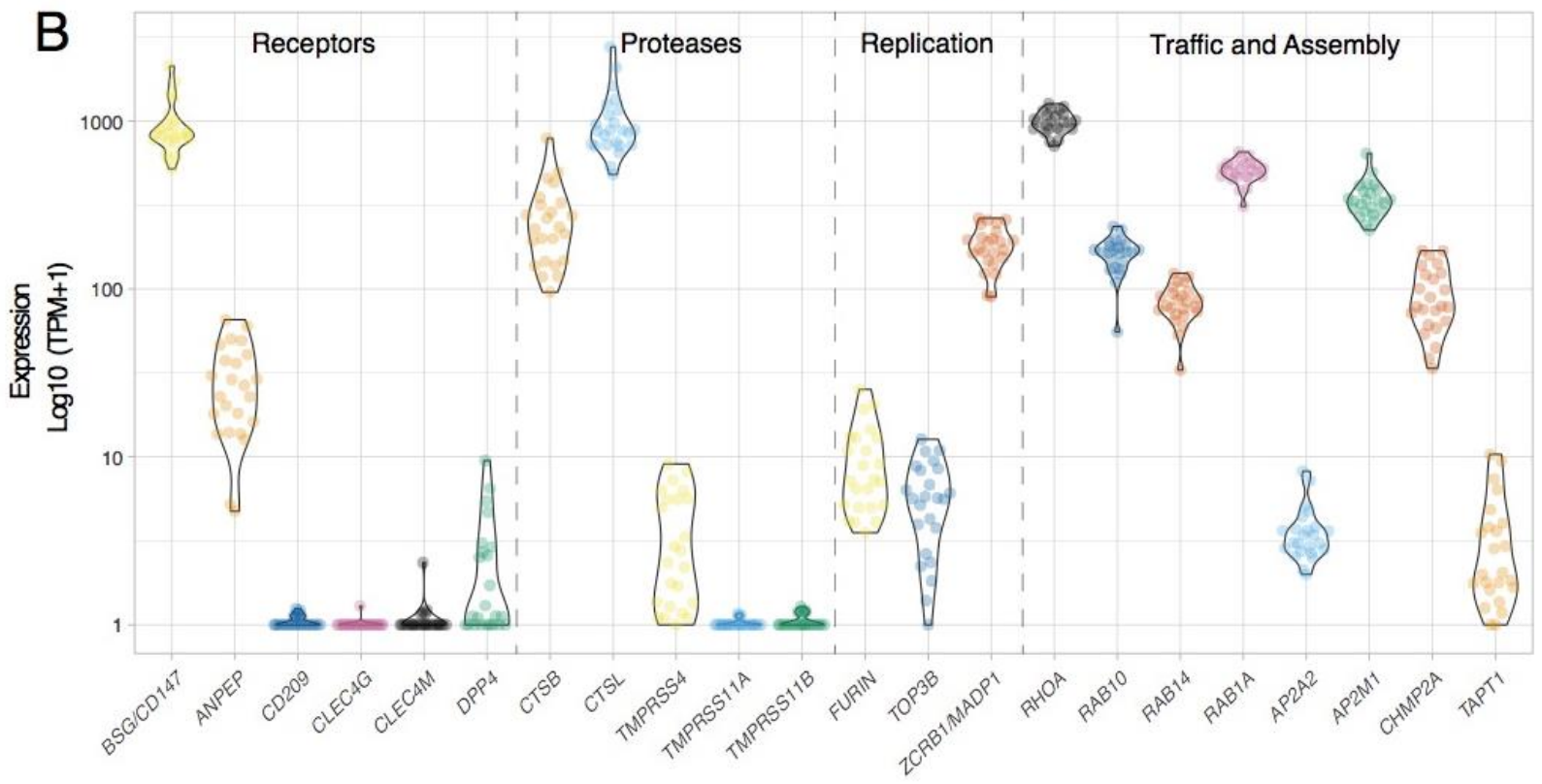

Figure 1 


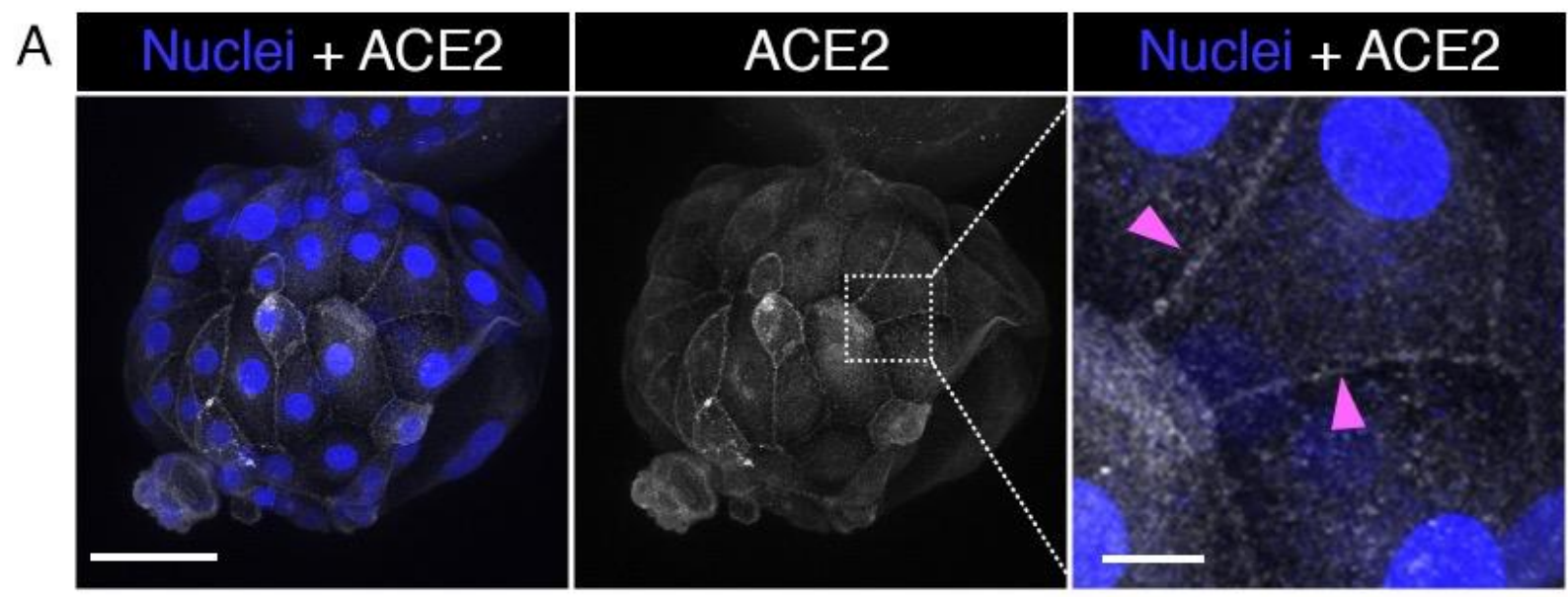

B Nuclei + TMPRSS2
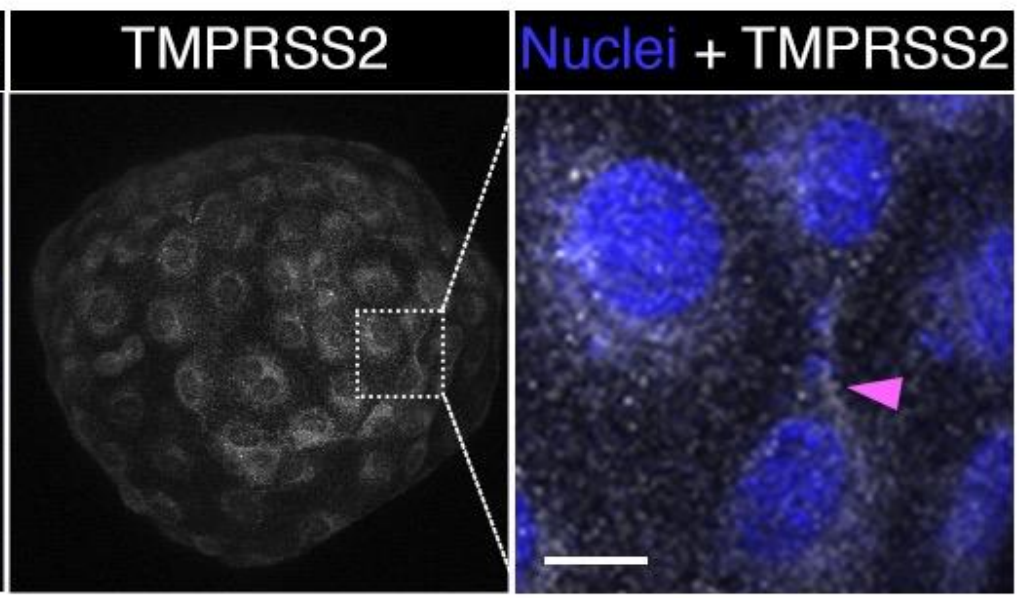

Figure 2 
bioRxiv preprint doi: https://doi.org/10.1101/2021.01.21.427501; this version posted January 21, 2021. The copyright holder for this preprint (which was not certified by peer review) is the author/funder, who has granted bioRxiv a license to display the preprint in perpetuity. It is made available under aCC-BY-ND 4.0 International license.
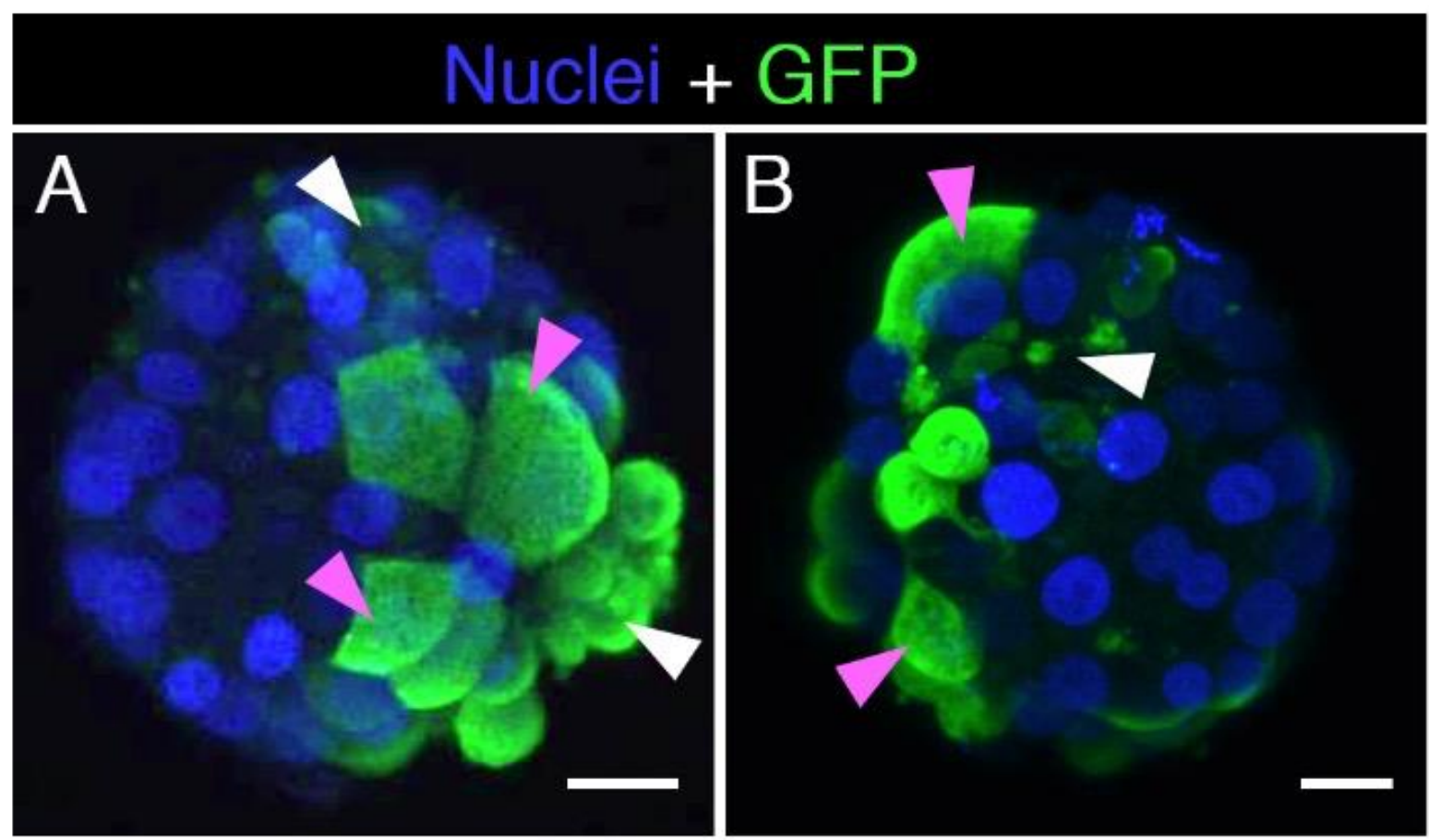

Figure 3 
bioRxiv preprint doi: https://doi.org/10.1101/2021.01.21.427501; this version posted January 21, 2021. The copyright holder for this preprint (which was not certified by peer review) is the author/funder, who has granted bioRxiv a license to display the preprint in perpetuity. It is made available under aCC-BY-ND 4.0 International license.
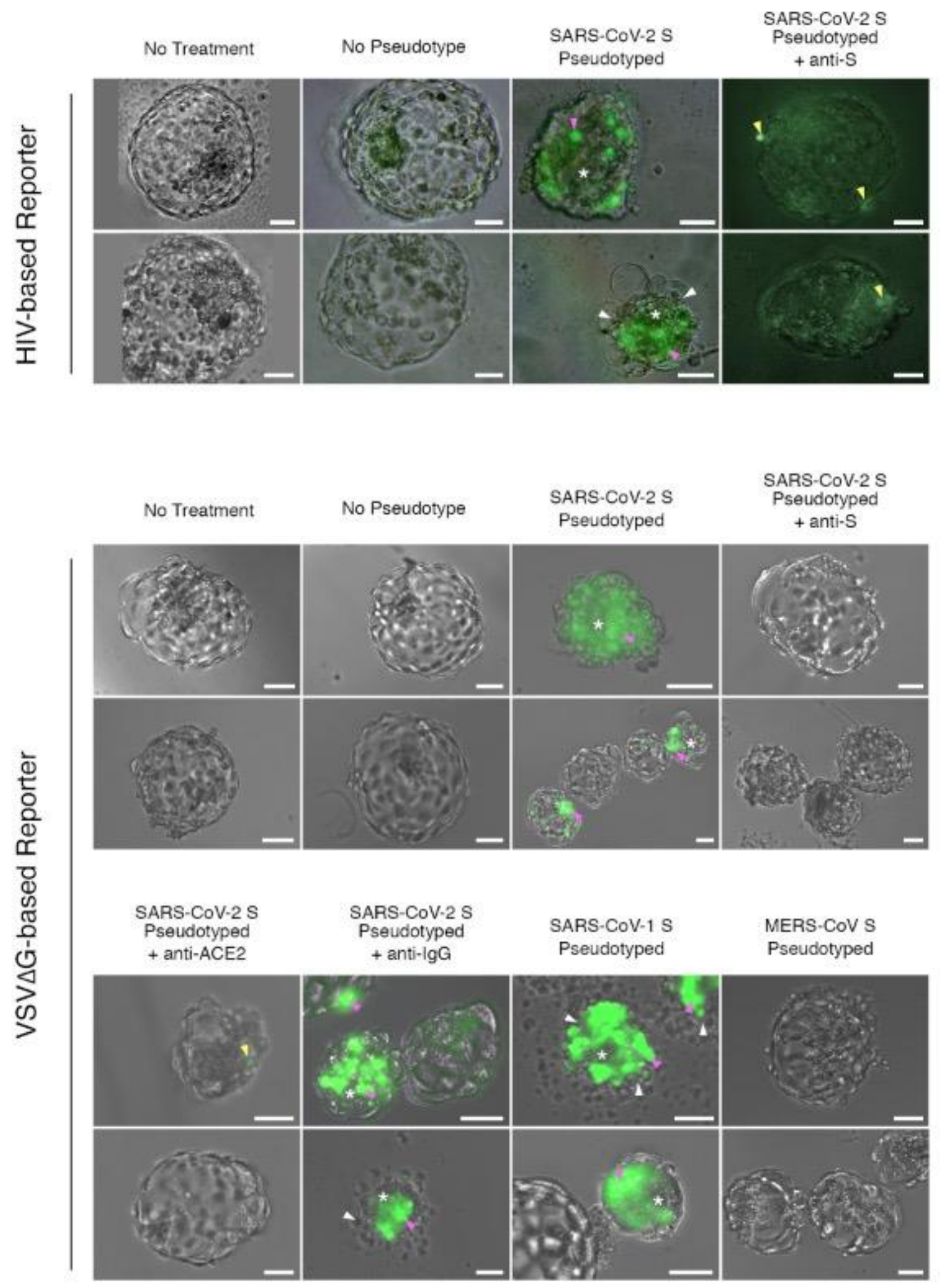

Supplemental Figure 1 


\section{Tables}

\section{Table 1}

\section{HIV-based Reporter}

\begin{tabular}{|l|l|l|}
\hline Treatment & $\begin{array}{l}\text { Number of Embryos } \\
\text { Tested }\end{array}$ & GFP Positive Embryos \\
\hline No Treatment & 15 & 0 \\
\hline No Pseudotype ('Bald') Virus & 15 & 0 \\
\hline SARS-CoV-2 Pseudotyped Virus & 15 & $6(40 \%)$ \\
\hline $\begin{array}{l}\text { SARS-CoV-2 Pseudotyped Virus } \\
\text { + anti-S neutralizing Antibody }\end{array}$ & 7 & $1(14.3 \%)$ with limited puncta \\
\hline
\end{tabular}

VSV $\Delta \mathrm{G}$-based Reporter

\begin{tabular}{|l|l|l|}
\hline Treatment & $\begin{array}{l}\text { Number of Embryos } \\
\text { Tested }\end{array}$ & GFP Positive Embryos \\
\hline No Treatment & 4 & 0 \\
\hline No Pseudotype ('Bald') Virus & 5 & 0 \\
\hline SARS-CoV-2 S Pseudotyped Virus & 7 & $4(57.1 \%)$ \\
\hline $\begin{array}{l}\text { SARS-CoV-2 S Pseudotyped Virus + } \\
\text { anti-S neutralizing Antibody }\end{array}$ & 4 & 0 \\
\hline $\begin{array}{l}\text { SARS-CoV-2 S Pseudotyped Virus + } \\
\text { anti-ACE2 neutralizing Antibody }\end{array}$ & 4 & $2(50 \%)$ with limited puncta \\
\hline $\begin{array}{l}\text { SARS-CoV-2 S Pseudotyped Virus + } \\
\text { anti-lgG neutralizing Antibody }\end{array}$ & 6 & $4(66.7 \%)$ \\
\hline SARS-CoV-1 S Pseudotyped Virus & 5 & $4(80 \%)$ \\
\hline MERS-CoV S Pseudotyped Virus & 5 & 0 \\
\hline
\end{tabular}




\section{Supplemental Table 1}

\begin{tabular}{|l|l|l|l|}
\hline $\begin{array}{l}\text { Embryo } \\
\text { Number }\end{array}$ & Ploidy & $\begin{array}{l}\text { Affected } \\
\text { Chromosomes }\end{array}$ & Ethnicity/Region \\
\hline 1 & Euploid & - & Central American (Mexico) \\
\hline 2 & Euploid & - & South Asian (India) \\
\hline 3 & Euploid & - & African/Mediterranean \\
\hline 4 & Euploid & - & European \\
\hline 5 & Euploid & - & African/Mediterranean \\
\hline 6 & Euploid & - & Middle Eastern (Jewish) \\
\hline 7 & Euploid & - & European \\
\hline 8 & Euploid & - & African/Mediterranean \\
\hline 9 & Aneuploid & +21 & East Asian (China) \\
\hline 10 & Aneuploid & $+7,-21$ & Central American/European \\
\hline 11 & Aneuploid & -15 & Central American/European \\
\hline 12 & Aneuploid & +5 & European \\
\hline 13 & Aneuploid & -17 & South Asian (India) \\
\hline 14 & Aneuploid & $-21,-22$ & Central American/European \\
\hline 15 & Aneuploid & $+7,+22$ & East Asian (China) \\
\hline 16 & Aneuploid & +4 & East Asian (Japan)/European \\
\hline 17 & Aneuploid & $+16,+20$ & East Asian (China) \\
\hline 18 & Aneuploid & $-15,+21$ & South-/East Asian (Vietnam/China) \\
\hline 19 & Aneuploid & +6 & South East Asian (Indonesia)/European \\
\hline 20 & Aneuploid & $+15,+16$ & East Asian (China) \\
\hline 21 & Aneuploid & $+11,+12,-22$ & East Asian (China) \\
\hline 22 & Aneuploid & -2 & East-/South Asian (China/India) \\
\hline 23 & Aneuploid & +16 & South Asian (India) \\
\hline 24 & Aneuploid & +15 & European \\
\hline & & &
\end{tabular}

